\title{
The resilient cycle network. The case study of Montesilvano
}

\author{
Antonio Alberto Clemente, Department of Architecture, University "G. d'Annunzio" of Chieti- \\ Pescara, IT \\ antonio.clemente@unich.it
}

\begin{abstract}
In recent years, in Montesilvano, the frequency of urban flooding resulting from extreme weather phenomena is strongly increasing. And it is precisely with reference to this phenomenon that the Research Convention between the Department of Architecture of Pescara and the Municipality of Montesilvano has inserted a line of investigation aimed at verifying whether between cycling networks, collection and management of meteoric water exists the possibility to establish a connection. Legislation, guidelines and best practices in his sector provide no useful indications. They are linked to a qualitative hypothesis whose priority in almost all cases focuses on creating the highest possible number of kilometres of safe, functional and intermodal cycling lanes. To identify operative references to the links between cycling lanes and stormwater management we must look at plans designed to contrast climate change. Many have a specific section dedicated to this theme: examples include Philadelphia, Copenhagen and Melbourne.

Their comparison reveals that improving stormwater management requires multiple actions. Principal actions include: breaking free of sector-specific logics, integrated projects for the spaces of the network and associated areas and the recognition of the importance of the relationship with context. In Montesilvano, marked by two parallel north-south axes (the Parkway and the Waterfront) and its five perpendicular east-west lines (Grandi alberghi, via Strasburgo, via Marinelli, via Torrente Piomba, Palaroma), the areas waiting for a project that can combine the mobility linked to the cycle network with the treatment and management of rainwater have been identified.
\end{abstract}

Keywords: Urban flooding, Soil sealing, Integrated project 


\section{Introduction}

Research Convention between the Department of Architecture of Pescara and the Municipality of Montesilvano has inserted a line of investigation aimed at verifying whether between cycling networks, collection and management of meteoric water exists the possibility to establish a connection. It is an important study because in recent years, in Montesilvano, the frequency of urban flooding resulting from extreme weather phenomena is strongly increasing. This situation is largely a result of excessive soil sealing and the overloading of the sewer network. This should come as no surprise, as Montesilvano is part of a more general story: the construction of the Adriatic city after the Second World War. The principal characteristic of this extraordinary growth was demographic. According to ISTAT, the population rose from little more than 7,000 people (1951) to almost 30,000 (1981), reaching more than 50,000 (2011). The registration of 54,000 residents in this town is proof that this growth continues. Population growth was accompanied by the phenomenon of second homes and hotel structures, built to satisfy the demand for seaside bathing. In addition, to better understand the phenomenon of soil sealing, it must be noted that the municipal area of Montesilvano measures little more than $23.57 \mathrm{~km}^{2}\left(2,300 \mathrm{res} / \mathrm{km}^{2}\right)$, situated between the coast line, important territorial infrastructures (the Adriatic railway, State Road 16, the A14 motorway) and the Saline River.

In Montesilvano, urban flooding resulting from extreme weather events is treated exclusively as an emergency. Instead, they should become a priority for the potential risks to the population and to the dangers that cultural, infrastructural and housing heritage could suffer.

\section{Regulations, Guidelines, Best Practices}

The study began by looking at urban planning regulations. In 1995, the principal concern expressed in the Direttive per la redazione, adozione ed attuazione dei Piani Urbani del Traffico (Directives for the Preparation, Adoption and Implementation of Urban Traffic Plans) in relation to pedestrians and cyclists, was to "provide all interventions useful and necessary for guaranteeing safety". Successively, in 1999, the Ministry of Public Works, together with the Ministry of Transport, issued the Regolamento recante norme per la definizione delle caratteristiche tecniche delle piste ciclabili (Regulation Containing Rules for Defining the Technical Characteristics of Cycling Lanes). The aims of this regulation included "favouring and promoting an elevated level of bicycle and pedestrian movement, as an alternative to the use of combustion engine vehicles in urban areas [...]; focusing on the attractiveness, continuity and recognisability of cycling routes [...]; evaluating the profitability of investments in relation to real and potential users and in relation to the objective of reducing the risk of accidents and levels of atmospheric and acoustic pollution; verifying the concrete feasibility and real utilisation of cycling lanes by users". In 2013, the strategic objectives for urban bicycle mobility in the Region of Abruzzo were: increasing the existing network of cycling lanes (privileging the creation of a network), improving safety, including the introduction of specific signage and the connection with the system of public mobility. The regulations for the preparation of the Biciplans (Bike Plans) contained in Law 2/2018 can be ascribed to a vast register: "towns not part of metropolitan cities and metropolitan cities are to prepare and adopt, in relation to their budget [...] and its eventual modifications, plans for urban bicycle mobility, known as "biciplans".

Another analytical approach is tied to the comparison between the extraordinary production of Guidelines. There are substantially five main areas of investigation: the identification of the network, 
signage, safety, materials and dimensional characteristics of cycling lanes. The objectives of the guidelines include the promotion of the use of the bicycle as a means of transport for movements between the home-work/school; clarifying the environmental, social and economic benefits linked to the use of the bicycle with respect to traditional forms of motorised mobility; guaranteeing an elevated standard of safety by minimising the risk of accidents or any other risk to cyclists; defining the most effective signage; identifying the geometric standards for the various typologies of paths, also considering that in PRESTO guideline it's written: "without cohesion there is no network, only a bunch of single routes. This is a matter of degree: the more routes interconnect and allow cyclists to freely choose their itinerary, the stronger the network is. For cyclists, cohesion is a very real quality: it is the extent to which they can reach their destination via the route of their choice."

As far as best practices are concerned, we referred to the Guida ai comuni ciclabili d'Italia (Guide to Bikeable Towns in Italy), published by the Federazione Italiana Amici della Bicicletta (FIAB). Evaluations in the Guide are based on four indicators. Bicycle tourism as an open and welcoming territory of paths, protected itineraries (urban and suburban) an dedicated services, including: bicycle repair shops, rental facilities, guides for cyclists and "bicycle friendly" hospitality structures. The second indicator is provided by urban mobility, which tends to verify actions taken by towns to reduce the use of the private automobile in favour of the bicycle. In particular, through the realisation of urban cycling lanes separated from ordinary street networks and the creation of $30 \mathrm{~km} / \mathrm{h}$ zones that limit traffic and speed. The third looks at Governance, intended as the capacity to accompany the realisation of infrastructures with a range of actions, including a reduction in the level of motorisation and the activation of policies for urban mobility, such as, for example, the nomination of mobility managers and regular home-school mobility services such as a bikebus. The final element involves strategic Communication linked to issues of sustainable mobility, which must be integrated with events and promotional activities intent on stimulating the use of the bicycle.

These brief considerations hint at how regulations and guidelines are linked to a framework of quantity. The priority appears to be the creation of the greatest number of kilometres of cycling lanes that are safe, functional and intermodal. That said the intention here is not to discuss the importance of regulations, guidelines or to explore best practices. Instead, the aim is to demonstrate that they are not sufficient to construct a network of cycling lanes able, even only in part, to take on the problems/opportunities offered by the territories it crosses. One example: is it possible that the construction of cycling lanes can contrast urban flooding caused by extreme climatic events? This question obliges us to broadening the horizon. To find operational references on the relationship between cycling networks and rainwater management it is necessary to look at the plans to combat climate change that have a specific section dedicated to this theme such as Philadelphia, Copenhagen, and Melbourne.

\section{Philadelphia, Copenhagen, Melbourne}

In Philadelphia, where the Green City-Clean Water plan, whose general aim is to avoid overloading the sewer network, is based on a number of cardinal criteria such as recharging water tables and maintaining and expanding water infrastructures. It is precisely in this direction that a network of cycling lanes, as part of an infrastructural system, enters the realm of planning. In particular, in the City of Philadelphia Green Streets Design Manual, which identifies six green stormwater infrastructures for the collection and management of stormwater in densely urbanised areas: permeable 
pavement whose porous surface and subterranean stone reservoir provide temporary storage, before the water filters into the ground, stormwater planters or rain gardens, stormwater bump-outs (midblock and corner), stormwater trees, stormwater tree trenches and green gutter.

Figure 1. Green stormwater infrastructures.

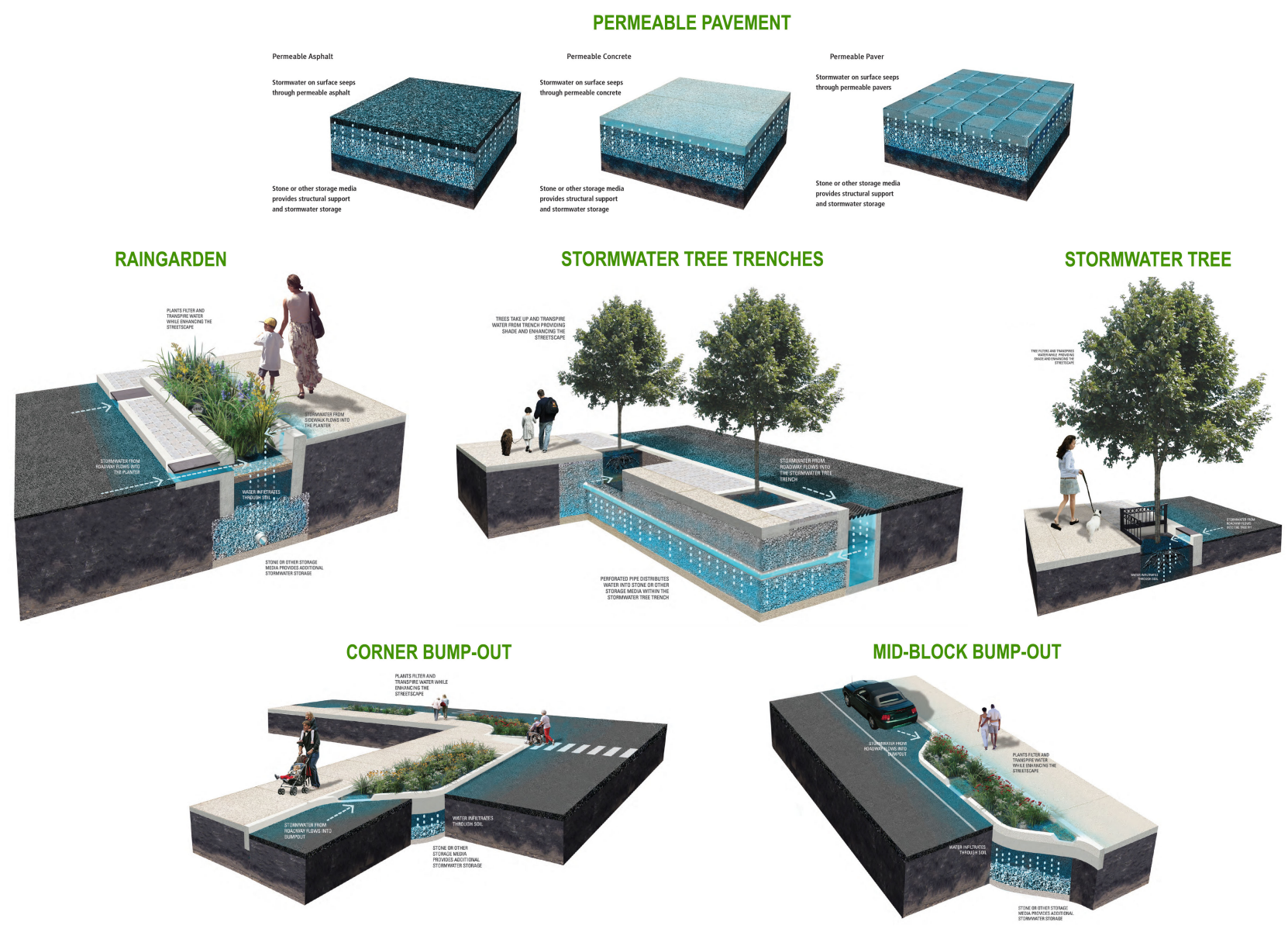

City of Philadelphia Green Streets Design Manual

Torrential rains have often flooded entire neighbourhoods in Copenhagen. The cause lies in the inability of the sewer network to handle the volumes of water created by these extreme atmospheric events. Solutions tested as part of the Climate Adaptation Plan include cloudburst streets: large green spaces that function as stormwater catchment areas. The precise objective of ensuring that even narrow streets can resist against urban flooding led to the creation of The Copenhagenize Current - Stormwater Management and Cycle Tracks. The strong idea is to provide the space beneath the city's vast network of bicycle lanes with a secondary system of stormwater channels and to improve the city's cycling infrastructure. 
Figure 2. The prefabricated concrete canals assumed in Copenaghen.

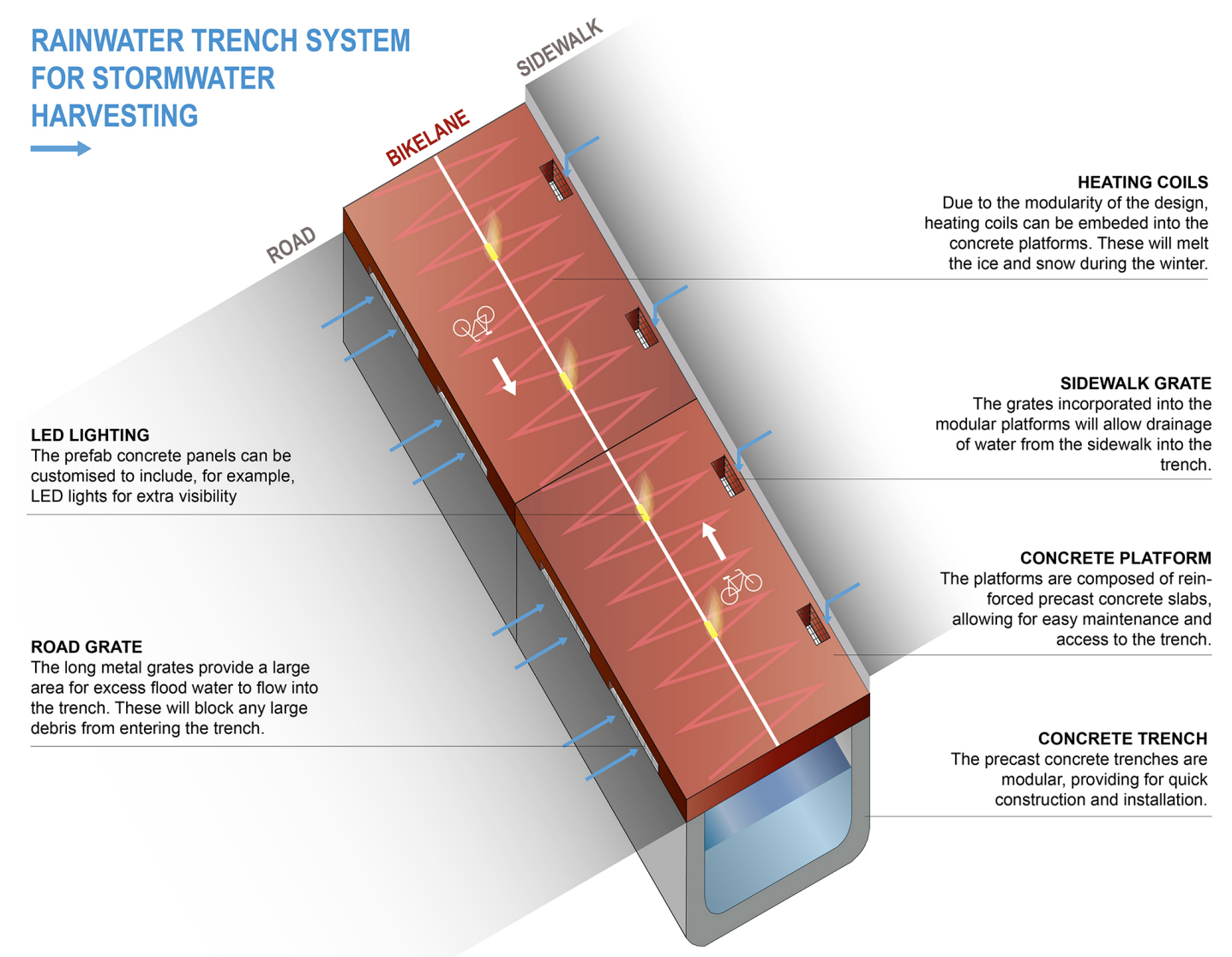

Original drawing by the architect Anna Laura Casiello

The La Trobe Street green bicycle lane is a new cycling lane with its own dedicated space. The design involves the narrowing of the roadbed and the modification of parking stalls. The lane is separated from the street by a traffic divider that also serves as a planting bed for trees. This bed is used to channel stormwater from the street and water that penetrates through the porous asphalt finish of the bike lane. The structure of the planting bed is designed to favour the passive irrigation of the tree roots. On the one hand this limits the risk of flooding and, on the other hand, helps reduce stormwater pollution.

Figure 2. Melbourne, section of the La Trobe Street green bicycle lane.

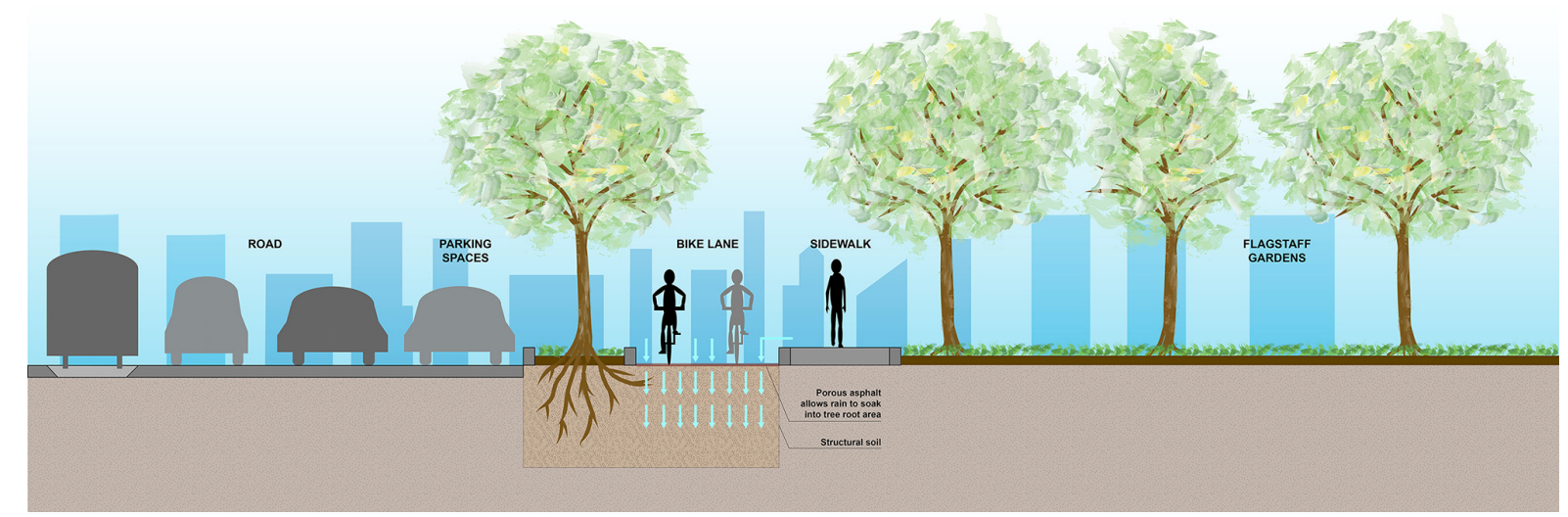

Original drawing by the architect Anna Laura Casiello 


\section{Few concluding observations}

These considerations raise a few questions: under what conditions can a network of bicycle lanes become part of an integrated project that helps improve stormwater treatment and management? The suggestions provided by Philadelphia, Copenhagen and Melbourne are clear: the network of cycling lanes is a project for the surface of the city whose realisation requires the integration between multiple lines of action.

There are three primary lines of action. The first concerns the need for a new point of view. In addition, we must also break free of sector-specific logics. The time has come to move beyond the idea that cyclists require a small highway offering mono-functional connections between different points in the city, the exclusive use of this space and a guarantee of safety. This network is not only an infrastructure for slow mobility, but also an urban system that, in this specific case, represents the space and grouping of systems used to treat and manage stormwater, as an alternative to the existing sewer network. This approach could be adopted in Montesilvano, given its current situation as a virtuous settlement with an important number of kilometres of existing bike lanes: the town has completed the entire section of the Adriatic Bike Network, under its responsibility and is listed in the Guida ai comuni ciclabili d'Italia.

However, this is not enough: dealing with a theme as vast as that of contrasting the negative effects of extreme climatic events cannot be limited to lip service, but must imagine a series of architectural devices able to serve, initially, as design hypotheses and, successively, as concrete responses. This is precisely the direction of the second line of action, in other words, the choice made, even if implicitly, in the City of Philadelphia Green Streets Design Manual, the La Trobe Street green bicycle lane and The Copenhagenize Current - Stormwater Management and Cycle Tracks: integrated intervention in the space of the network and the associated areas adjacent to this infrastructure or in its immediate surroundings. This is why Montesilvano must once again reflect on the role of its two parallel northsouth axes (Parkway and Waterfront) and its five perpendicular east-west axes (Grandi alberghi, via Strasburgo, via Marinelli, via Torrente Piomba, Palaroma), to understand where to use draining surfaces, stormwater outflow channels or stormwater infrastructures.

This choice must necessarily take into account geomorphological conditions, road sections, the possibility - or not - to integrate the system of underground services and, more in general, the technical and economic feasibility of similar operations. This is where the third line of action becomes fundamental: emphasising the importance of the relationship with context. Working with the hypothesis that a network of bicycle lanes is a relational project obliges us to pay more attention to urban identities; to the particular nature of parts of the city; to assume the centrality of the notion of public space.

In Montesilvano this is the way to clearly identify those areas that conceal the signs of expectation of a project that successfully unites the network of bicycle lanes with stormwater treatment and management. 
Figure 4. Montesilvano: identification of potential axes of stormwater treatment and management.

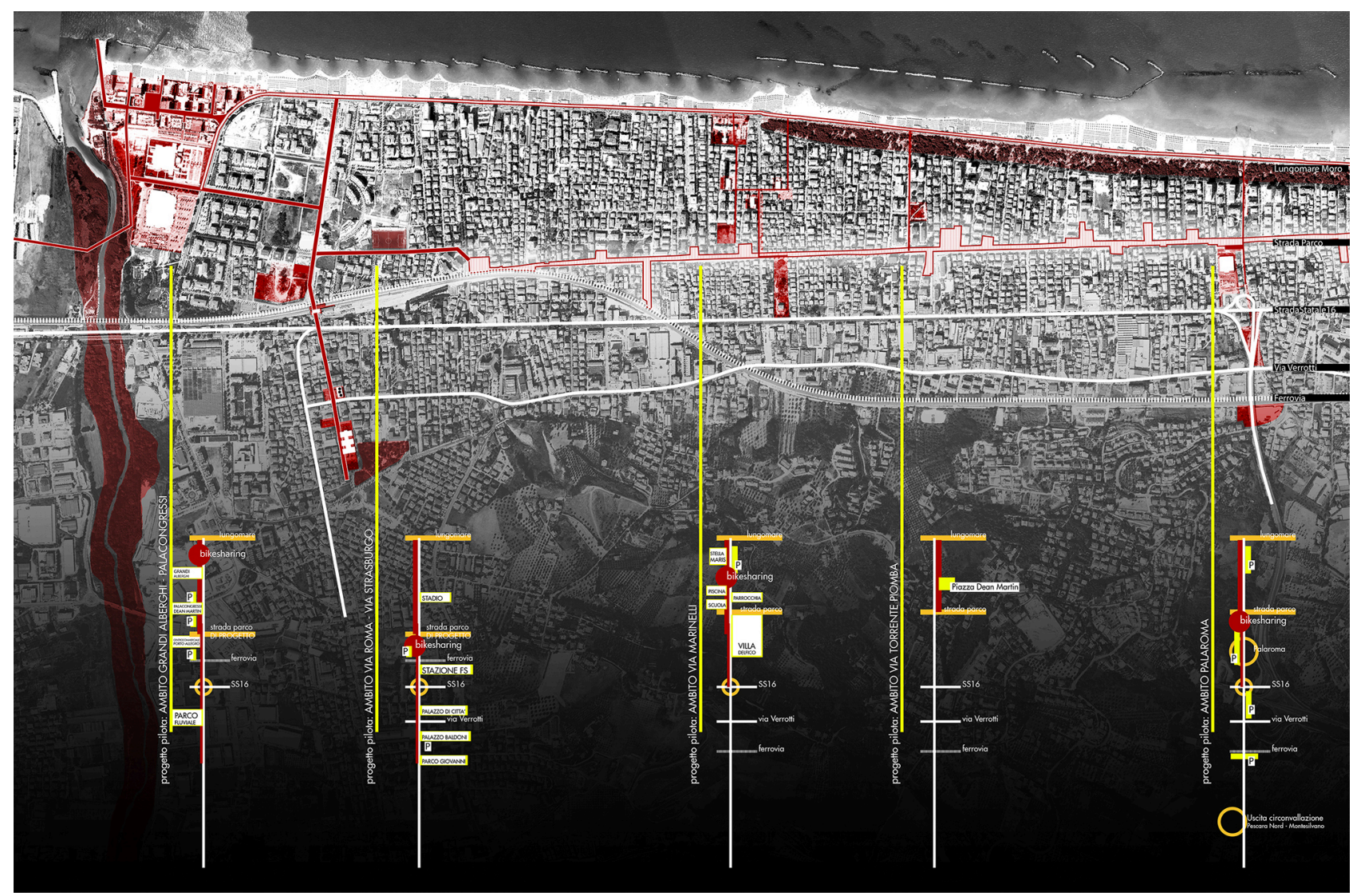

Source: original drawing by architects Giulio Girasante and Paolo Chiavaroli

\section{Acknowledgments}

The inter-institutional collaboration between the Department of Architecture of Pescara and the City of Montesilvano, in coherence with the Protocol of Understanding, is for a two-year period (2018/2019). Research team: Research Coordinator - prof. Paolo Fusero; Research Coordination - prof. Antonio Alberto Clemente; Scholarship students - architects Giulio Girasante, Paolo Chiavaroli; Collaborators - arch. Paride Taurino, ing. Francesco Rossi, ing. Cristina Affatato, Giuseppe Leone, Pierluigi Petaccia, Giuseppe D’Abbraccio, Angelica Nanni.

\section{Conflict of Interest}

The authors declare no conflict of interest

(C) 2018 by the authors; licensee MDPI and IFoU, This article is an open access article distributed under the terms and conditions of the Creative Commons Attribution license. 